\section{Evaluation of urbanization influences on urban temperature of Nairobi City, Kenya}

\author{
Victor Ongoma, ${ }^{1}$ John N. Muthama, ${ }^{2}$ \\ Wilson Gitau ${ }^{2}$ \\ ${ }^{1}$ Kenya Meteorological Department, \\ Nairobi; ' ${ }^{2}$ Department of Meteorology, \\ University of Nairobi, Kenya
}

\section{Abstract}

Developing countries are becoming more urbanized leading to modification on climate over the cities. Proper urban atmospheric planning and management are thus fundamental for cities' sustainability. Urban weather and climate therefore needs continuous monitoring to offer accurate, reliable and timely update of any significant changes. This study examined the long term modification of temperature by urbanization utilizing decadal population data, monthly maximum and minimum temperature and land surface albedo for forty years. The data were subjected to homogeneity test using Short-Cut Bartlett test method that showed both maximum and minimum temperature increasing, though insignificant. Urbanization is evidenced by the reducing land surface albedo and increasing population. The study revealed the influence of urbanization on urban climate. The increase in temperatures is harmful to human comfort. Practical approaches, such as increasing the urban forest cover and a proper planning of the cities, have been suggested to help prevent further modification of weather and urban climate by urbanization. The findings of this work are thus important for multi-sectoral use in the Kenyan cities.

\section{Introduction}

Population growth leads to growth of urban areas, it involves land-use changes that are due to human activities. The process of urbanization entails the construction of buildings, roads, and increase in traffic that creates climate of its own. Land-use changes are becoming factors in the alteration of local and regional climate. In the process of urbanization, more energy is received and retained owing to increase greenhouse gases into the atmosphere. $^{1}$

According to UNEP, Africa's urban areas are expanding rapidly, growing at the fastest world annual rate of $3.5 \%{ }^{2}$ The growth of the urban centres generates a lot of challenges, economically, socially and environmentally. The effects of urbanization on the microclimate of cities are mostly due to the changes in the various land uses. ${ }^{3}$

\section{Problem statement, objective and justification of the study}

Previous studies show that urbanization effects on weather and climate are noticeable even in population settings of as small as 1000 and the intensity of urban heat island is linearly correlated with the logarithms of the population. ${ }^{4}$ Karl et al. studied the relationship between urban growth using population as an indicator of urbanization and the mean annual and seasonal temperatures in United States using diurnal maximum, minimum and average temperature and temperature range. ${ }^{5}$ The results showed that urban effects on temperature range were detectable even for small towns with mean population of 10,000 .

The potential increasing temperatures and air pollution coupled with a projected doubling of the global urban population by 2030 greatly elevates the need for urban climatology in devising effective strategies for managing climate in large cities. ${ }^{6}$ This study hypothesized that the population increase associated with urbanization will lead to modification on the urban climate. The study aims at evaluating the temporal patterns of urbanization and investigation of urbanization effects on temperature, which will be vital in enhancing human comfort as well as ensuring environmental sustainability.

\section{Study area}

Nairobi is the Kenya's largest and capital city. It is centrally located $1^{\circ} 9^{\prime} \mathrm{S}, 1^{\circ} 28^{\prime} \mathrm{S}$ and $36^{\circ} 4^{\prime} \mathrm{E}, 37^{\circ} 10^{\prime} \mathrm{E}$, and has an area of $684 \mathrm{~km}^{2}$. It holds a population of 3.1 million people. ${ }^{7}$

\section{Literature review}

Urban climatological research around the world has focused on many areas, including Urban Heat Island (UHI) and the effects of urban growth on temperature. Okoola's investigation of UHI using 9-year minimum and maximum temperature observations over the city of Nairobi revealed that the maximum UHI intensity lay to the north east of the main city centre. ${ }^{8}$ The annual trends in surface temperature exist at all stations in Nairobi city with higher rates of change in annual minimum temperature compared to the annual maximum temperature. ${ }^{9}$ The rates of surface temperature were higher for sub-urban stations compared to urban stations. The results also revealed an earlier warming in mean annual minimum temperatures at the urban location.

Oke measured urban albedo and found it to range from 0.08 to 0.20 in United States' cities
Correspondence: Victor Ongoma, Kenya Meteorological Department, Ngong Road, 3025900100 Nairobi, Kenya.

Tel. +254.20.3867880 - Fax: +254.20.3876955.

E-mail: victor.ongoma@gmail.com

Key words: urbanization, urban heat island, modification.

Contributions: the authors contributed equally.

Conflict of interests: the authors declare no potential conflict of interests.

Received for publication: 10 October 2012.

Revision received: 18 January 2012.

Accepted for publication: 18 January 2012.

This work is licensed under a Creative Commons Attribution 3.0 License (by-nc 3.0).

(C) Copyright V. Ongoma et al., 2013

Licensee PAGEPress, Italy

Global Meteorology 2013; 2:e1

doi:10.4081/gm.2013.e1

attributing it to complicated urban surface geometries. ${ }^{10}$ This arises following multiple reflections and trapping of radiation with the canyon spaces.

Zhou et al. studied significant urbanization effect on climate in China. ${ }^{11}$ This study found that daily minimum temperature rise faster than the daily maximum temperature. Chen $e t$ al. carried out an the investigation of UHI intensity during the period of 1961-2000 in Wuhan by analyzing annual mean, mean minimum and maximum temperature anomalies from a set of one rural station and four urban stations. ${ }^{12}$ The study found out that significant warming of mean minimum temperature and annual mean temperatures occurred at all stations but the warming being significantly larger at the urban station.

According to Kovats and Aktar, most cities in Africa, Asia and Latin America, and the Caribbean will experience more heat waves depending on the background climate. ${ }^{13}$ Mitigation concepts for UHI are very necessary. In the investigation by Stone and Norman on the influence of the size and material composition of built up zones on UHI intensity, they found that the contribution of individual land patches to regional heat island formation could be reduced by $40 \%$ if suitable land-use planning policies are adopted. ${ }^{14}$

According to Zhang, land surface albedo is one of the most important parameters characterizing the earth's radiative regime and its impact on biospheric and climatic processes. ${ }^{15}$ A study by Jin et al. showed that urban regions reduce the albedo by replacing the vegetationcovered natural surfaces with human constructions. ${ }^{16}$ 


\section{Materials and Methods}

The data used in the study can be grouped into three classes, namely in situ observed weather data, satellite observed land surface reflectivity data, and demographic data. Monthly maximum and minimum temperature utilized to study local climate modification were sourced from Kenya Meteorological Department (KMD) for a number of representative stations (Table 1) from 1970s to 2010s.

Land surface reflectivity was obtained from Moderate-resolution Imaging Spectrometer (MODIS). The monthly data spanning from August 2002 to December 2005 was acquired at a resolution of $500 \mathrm{~m}$. The actual reflectivity was obtained getting the difference between the reflectivity recorded under total sky and under clear sky.

Population data was obtained from the Kenya National Bureau of Statistics dating from 1969 to 2009 for census results of 1969 , 1979, 1989, 1999 and 2009 and population projections for years between the census years.

Temperature data was passed through a quality control procedure with the purpose of identifying outliers in the time series. This method was useful for the test constancy of variability in a time series and was applied by dividing the series into $k$ equal sub-periods, where $k>2 .{ }^{17}$ In each of these sub-periods, the sample variance $S_{k}$ is given by equation 1:

$$
S_{k}^{2}=\frac{1}{n}\left[\sum x_{i}^{2}-\frac{1}{n}\left(\sum x_{i}\right)^{2}\right]
$$

where the summations range over the $n$ values of the series in the sub-period $k$. The analyses in the study had 6 sub-periods $(k)$ and 62 and $40 n$ values for maximum temperature and minimum temperature, respectively. The variation in the number of $n$ values was due to varying lengths of data sets for the respective parameters.

The largest and smallest values of $\mathrm{S}_{\mathrm{K}}{ }_{\mathrm{K}}$ were selected and denoted as $\mathrm{S}_{\text {max }}{ }_{\text {max }}$ and $\mathrm{S}_{\text {min }}^{2}$ respectively. The $95 \%$ significance points for the ratio $\mathrm{S}_{\text {max }}^{2} / \mathrm{S}^{2}{ }_{\text {min }}$ was obtained by comparing this ratio with the values in F-distribution table $\mathrm{F}$. The null hypothesis was rejected if the F-calculated value was less than the F-tabulated value.

The F-test used in analysis of variance problem with $k$ factors can be sensitive to unequal standard deviations in the $k$ factors. The sampling distribution of the Bartlett statistics is approximately chi-square when the $k$ factor samples are from independent normal populations. Bartlett's test can be sensitive to departures from this normality assumption.

The Mann-Kendall rank statistics was used to detect abrupt changes in the weather parameters. The method is considered the most appropriate for analysis of climatic changes in climatological time series for detecting climatic discontinuity. ${ }^{18}$ The test uses the ranks $y_{i}$ of all the terms, $x_{i}$ in a series under analysis when arranged in increasing order of magnitude. For each element $y_{i}$, the number $n_{i}$ of element $y_{i}$ preceding it $(i>j)$ is calculated such that $y_{i}>y_{\mathrm{j}}$. The test statistics is given by equation 2 :

$$
\mathrm{t}_{\mathrm{i}}=\sum_{i} n_{i}
$$

and its distribution function under the null hypothesis is asymptotically normal, with mean:

$$
E\left(t_{i}\right)=\frac{\mathrm{n}(\mathrm{n}-1)}{4}
$$

and variance:

$$
\operatorname{Var}\left(t_{i}\right)=\frac{\mathrm{n}(\mathrm{n}-1)(2 \mathrm{n}+5)}{72}
$$

In the absence of any assumptions regarding the existence of a trend in a given direction, the test is correct only if its two-sided form is adopted, that is to say if the null hypothesis is rejected for large values of $u\left(t_{i}\right)$, where:

$$
u\left(t_{i}\right)=\frac{\left[\mathrm{n}\left(\mathrm{t}_{\mathrm{i}}\right)-\mathrm{E}\left(\mathrm{t}_{\mathrm{i}}\right)\right]}{\sqrt{\operatorname{Var}\left(\mathrm{t}_{\mathrm{i}}\right)}}
$$

In these conditions, a probability ${ }_{1}$ is determined using a standard normal distribution table such this:

$$
\alpha_{1}=\mathrm{P}\left(|\mathrm{u}|>\left|\mathrm{u}\left(\mathrm{t}_{\mathrm{i}}\right)\right|\right)
$$

The null hypothesis is accepted or rejected at the level $\alpha_{0}$ depending on whether $\alpha_{1}>\alpha_{0}$ or $\alpha_{1}<\alpha_{0}$. When the values of $u(t)$ are higher (in absolute value) than 1.96 , an increasing or decreasing trend can be observed depending on whether $u\left(t_{i}\right)$ is positive or negative. When a series shows a significant trend, we wish to locate the start of the phenomena by means of a sequential analysis. In this case, it can be usefully extended to the reversed series. Therefore, we calculate the number $n_{i}$ of $y_{i}$ terms for each $y_{i}$ term such that $y_{i}>y_{\mathrm{j}}$ with $i<j$, which gives a check on the first calculation, given:

$n_{i}=y_{i}-1-n_{i}$

so that:

$\mathrm{i}=(N+1)-1$

where $N$ is the total number of observations in the series. Therefore the values of $u^{\prime}\left(t_{i}\right)$ for the reversed series can be calculated similar to $u\left(t_{i}\right)$. In the absence of any trend in the series, the graphical representation of $u$ and $u$ in terms of $i$ generally gives curves which overlap several times.

A linear regression model was applied to show the relationship between land surface albedo and temperature. In the relation, if $Y$ is a linear function of $X$, then:

$$
Y=\mathrm{a}+\mathrm{b} X+\mathrm{e}
$$

where e is random error and $b$ a coefficient of $X$. The coefficient b of $X$ represents the amount of change in $Y$ corresponding to one unit change in $X$.

\section{Results}

The homogeneity test was carried out using the Short-Cut Bartlett test and found to be homogeneous (Figures 1 and 2). In other studies, Makokha studied long term urban modification of mean annual surface temperature in Nairobi city, performed the homogeneity test on annual temperature, the data was found to

Table 1. Meteorological stations used in the study.

\begin{tabular}{lccccc} 
Station & Altitude & Longitude & Latitude & \multicolumn{2}{c}{ Data length } \\
& & & & From & To \\
MAB & 1637 & 36.867 & -1.267 & 1975 & 2008 \\
Dagoretti & 1798 & 36.750 & -1.300 & 1975 & 2010 \\
\hline Wilson & 1676 & 36.820 & -1.320 & 1975 & 2010 \\
Jomo Kenyatta International Airport & 1615 & 36.920 & -1.320 & 1975 & 2010 \\
\hline Kabete Agromet & 1941 & 36.750 & -1.270 & 1975 & 2008 \\
Muguga KARI & 2096 & 36.630 & -1.220 & 1975 & 2010 \\
\hline
\end{tabular}

MAB, Moi Air Base; Muguga KARI, Muguga Kenya Agricultural Research Institute. 
be homogeneous. ${ }^{9}$

The data was thus recommended and used in further analysis to achieve the objectives of the study.

\section{Mann-Kendall analysis}

The Mann-Kendall analysis was used to detect abrupt changes in the weather parameters used in the study. The test statistic values were tested at $95 \%$ standard normal distribution significance. The graph of $U(t i)$ is the forward sequential statistics and the $U\left(t i^{\prime}\right)$ is the backward sequential statistics. The intersection of the two curves shows the probable beginning of an abrupt climatic change, i.e. the beginning of a trend in this study.

The temperatures recorded an increasing trend. The increase in maximum temperature is observed to start in 1994 (Figure 3).

It is evident from the analysis that increases in minimum temperature started in early 1990s (Figure 4). These results agree with the results carried out over the city of Cairo in 1995-2002 by Robaa that showed both maximum and maximum temperatures increasing over the city as it continued to grow. ${ }^{19}$

Mann-Kendall analysis shows an increase in maximum and minimum temperature, though the changes are not significant.

Albedo is one of the most important parameters for characterizing the earth's radiative regime and its impact on climatic processes. Land use changes in urban centres, concrete and buildings among others have a lower albedo than rural areas with trees and vegetation. Nairobi has reported urbanization from August 2002 to March 2005 (Figure 5).

This observation is in conformity with a study carried out by Arnfield. ${ }^{20}$ The albedo values over the three cities were mainly confined between 0.04 and 0.25 with an average value of 0.104 . The reflectivity in these cities closely agrees with the findings by Oke who measured values of albedo in urban areas and found out that they range from 0.10 to 0.27 , with a mean value near to $0.15 . .^{10}$

\section{Population}

Population trend depicts urban growth (Figure 6).

It is thus expected that the impacts of urbanization on urban climate will be pronounced.

It is observed that the maximum temperature city changes inversely as reflectivity (Figure 7). The coefficient of determination of maximum temperature is generally higher than the coefficient of determination of minimum temperature by land surface reflectivity.

The coefficient of determination of maximum temperature by albedo over Nairobi city is 0.411 (Figure 7).

There is an observed increase in minimum temperature over all the cities and is thus negatively correlated to land surface reflectivity. A small percentage of change in minimum temperature, approximately $2 \%$, can be explained by the change in land surface reflectivity over Nairobi (Figure 8).
Generally, there is notable increase in both maximum and minimum temperatures over the city with time. This implies that cities are generally becoming warmer. The observation is in agreement with other studies that have been carried out; as early as 1970s, Oke

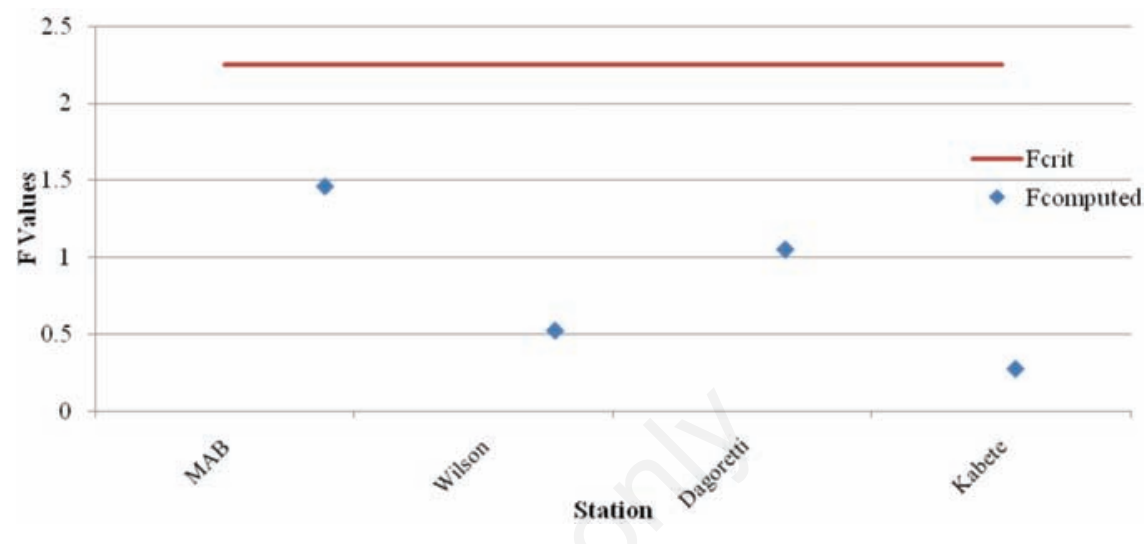

Figure 1. Maximum temperature homogeneity test (computed F-value and critical Fvalue).

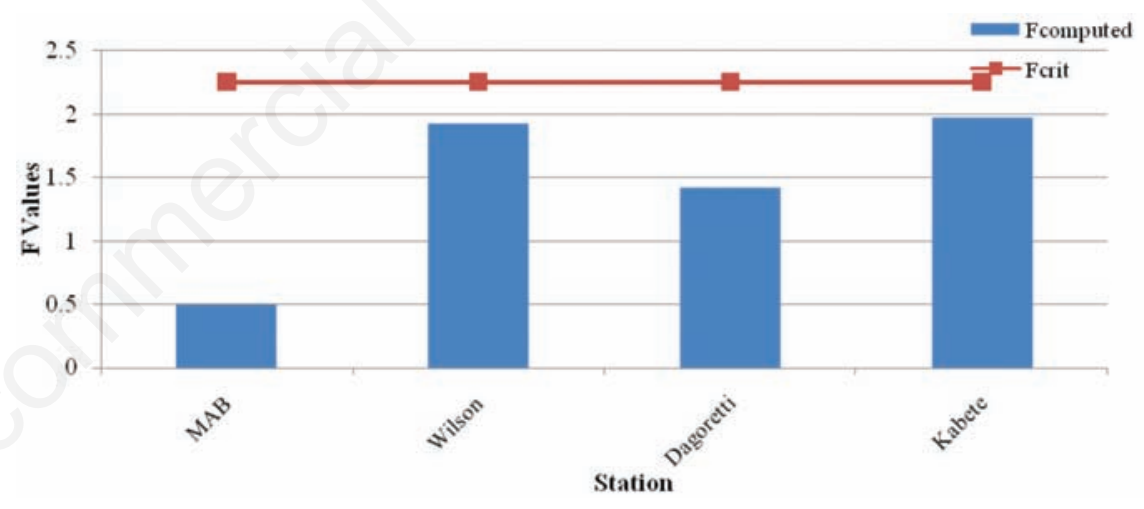

Figure 2. Minimum temperature homogeneity test (computed F-value and critical Fvalue).

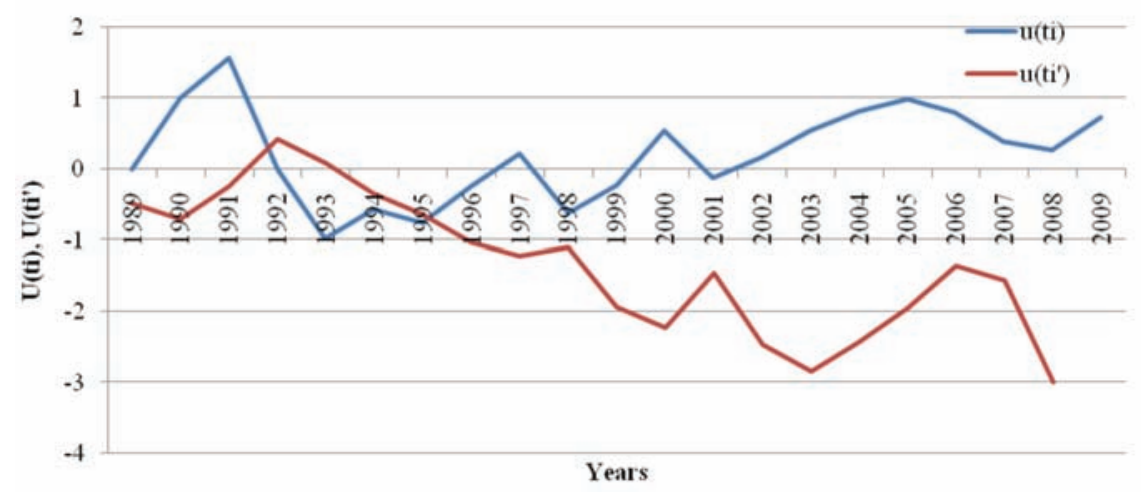

Figure 3. Mann-Kendall test for Nairobi maximum temperature. U(ti) is the forward sequential statistics and the $\mathrm{U}\left(\mathrm{ti}^{\prime}\right)$ is the backward sequential statistics. 
noticed the higher temperatures over urban centres as compared to rural country side in America. ${ }^{4}$ Spronken-Smith and Oke observed similar results and explained it by an increase in the density of buildings in urban areas, the energy from anthropogenic activities and the change in non-permeability of the ground surface in urban settings. ${ }^{21}$

Temperature trends indicate that minimum temperature is rising faster than maximum temperature. Recent studies carried out in China conform to the observations; Zhou et al. and Chen et al. found out that minimum temperatures rise faster than maximum temperatures over the cities. ${ }^{11,12}$

\section{Discussion}

Nairobi city is getting more urbanized. This is evidenced by population and land surface reflectivity changes. Population growth in the city is partly explained by net migration into the city. ${ }^{22}$ A number of factors explain this, e.g. search for opportunities for higher education and employment.

The land surface reflectivity is observed to decrease over the cities with time. This can be explained by the dense building regions that have canyon effect, which limits the number of solar photons of solar energy reflected back to the atmosphere. Temperatures, both maximum and minimum, are observed to increase over the city with the minimum increase at higher rate than the maximum. The increase in temperature in the cities is attributed to human activities such as increase waste disposal that decompose to generate heat, heat emission from industries and vehicles, materials of urban structures and urban surface cover. The metallic materials used in construction and the concrete pavements in the city absorb a lot of heat, thus increasing the urban temperature.

\section{Conclusions}

The change in minimum temperature during the study period is higher as compared to maximum temperature; this is due to the effect of urbanization coupled with the global warming. Although changes in temperature under study were found to be insignificant, the changes indicate the warming of the cities. The same observations were made on correlating population with the parameters.

The city has experienced a decrease in reflectivity indicating the city's growth. The population is observed to increase with time as well. Following the observed modification on urban climate by urbanization, the environ-

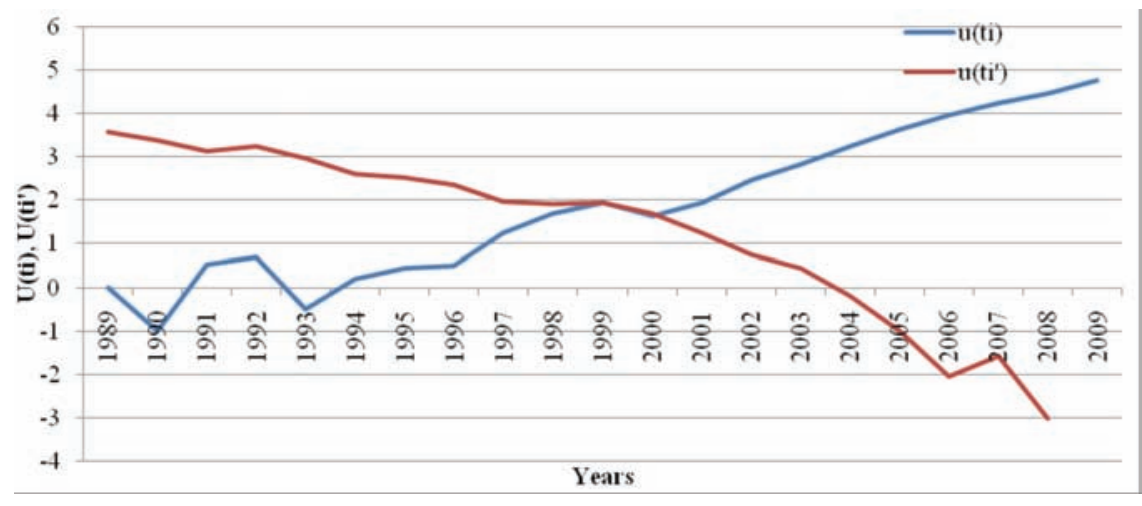

Figure 4. Mann-Kendall test for Nairobi minimum temperature. U(ti) is the forward sequential statistics and the $U\left(t^{\prime}\right)$ is the backward sequential statistics.

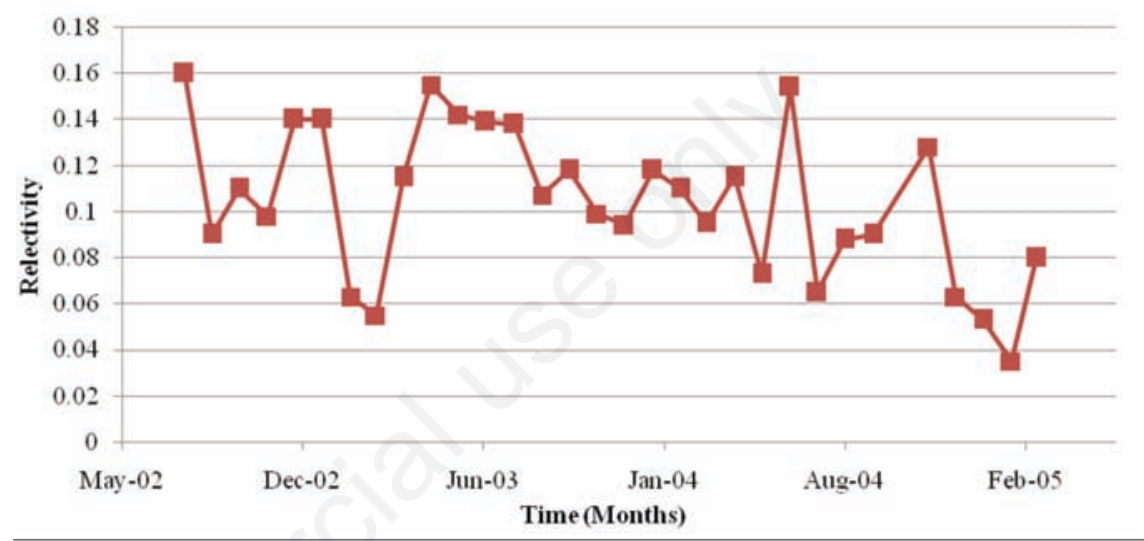

Figure 5. Land surface reflectivity over Kenyan cities against time.

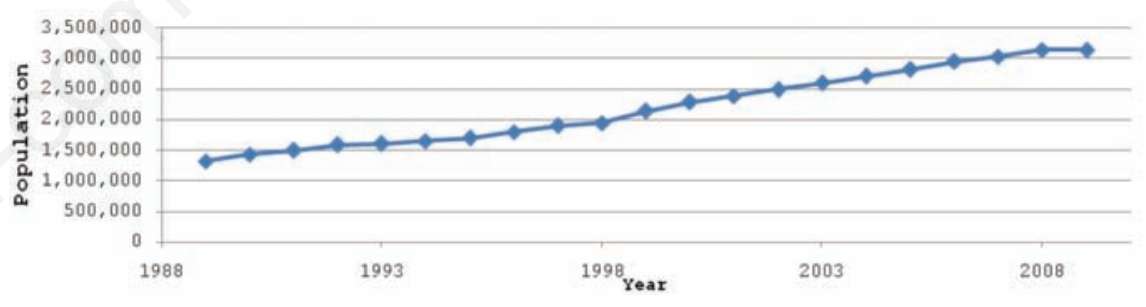

Figure 6. Population trend over Nairobi.

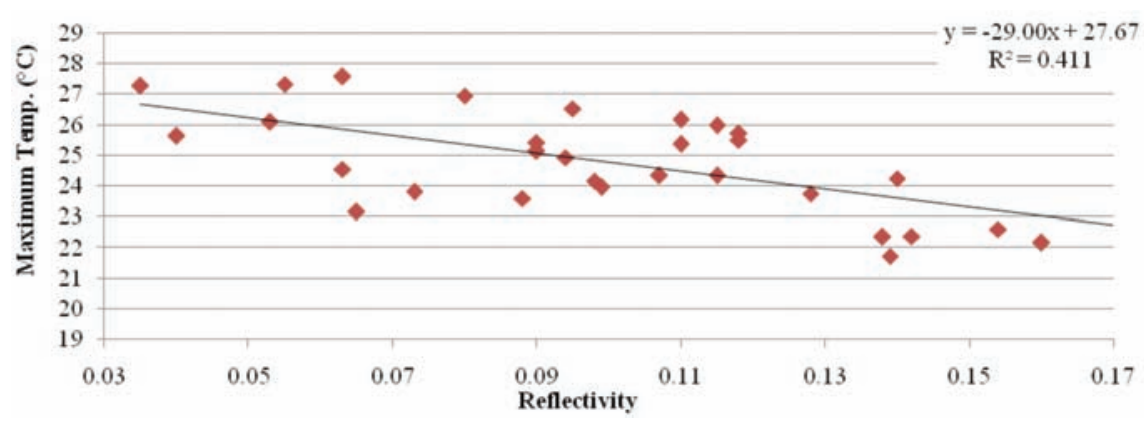

Figure 7. Regression of maximum temperature and land surface reflectivity over Nairobi. 


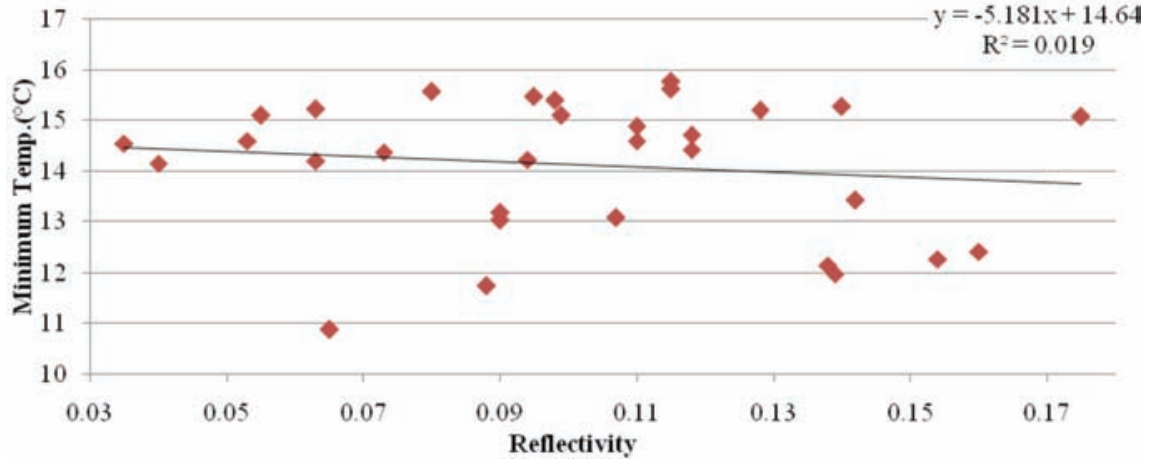

Figure 8. Regression of minimum temperature and land surface reflectivity over Nairobi.

mental effect of such urban weather modification on human comfort is thus inevitable. This information is therefore of value to building designers, city dwellers, event organizers, health practitioners, city planners among others to enhance safe stay and environmental sustainability.

Despite the fact that urban settings face many environmental challenges, proper structural planning, outdoor events planning and choice of settlement and industrial zones can help address some of the issues. This study recommends that the government should work towards increasing the network of meteorological observing/monitoring stations especially in urban centres. This should be done in order to provide enough data to promote comprehensive studies on the effects of the dynamic urbanization on weather and climate.

Enacting green and sustainable development policies to help increase land's green cover: increase in vegetation cover is highly recommended as a remedy measure. Decentralization of important social amenities and relo- cation of cities will help relieve congestion in the city.

\section{References}

1. Figuerola PI, Mazzeo AN. Urban-rural temperature differences in Buenos Aires. Int $\mathrm{J}$ Climatol 1998;18:1709-23.

2. UNEP. Africa environmental outlook 2: our environment, our wealth. Nairobi: United Nations Environment Programme ed.; 2006.

3. Nduka IC, Abdulhamed AI. Classifying urban climate field sites by thermal climate zones. The case of Onitsha metropo lis. Res J Environ Earth Sci 2011; 3:75-80.

4. Oke TR. City size and urban heat island. Atmos Environ 1973;7:769-79.

5. Karl TR, Diaz HF, Kukla G. Urbanization: its detection and effects in the United States climate record. J Climate 1988;1:1099-123.
6. UN. World urbanization prospects: the 1999 revision. Washington, DC: United Nations ed.; 2001.

7. KNBS. Kenya Population Census, 2009. Nairobi: Kenya National Bureau of Statistics ed.; 2010.

8. Okoola RE. The Nairobi heat island. Kenya J Sci Technol Ser A 1980;1:53-61.

9. Makokha GL. Long term urban modification of mean annual surface temperature in Nairobi City, Kenya. In: Proceedings of the Sixth Workshop on Meteorological Research and Applications and Services, 2003 Sept 29-0ct 3, Mombasa, Kenya. Nairobi: Kenya Meteorological Society ed.; 2003. pp 211-7.

10. Oke TR. Boundary layer climates. 2nd ed. London/New York: Methuen; 1987.

11. Zhou L, Dickinson RE, Tian Y, et al. Evidence for a significant urbanization effect on climate in China. P Natl Acad Sci USA 2004;101:9540-4. Available from: http://www.pnas.org/content/101/26/9540.f ull? sid= 1 bfd5e 69-1447-497d-ba29f47761d9fd58 Accessed: 10/12/2011.

12. Chen ZH, Wang HJ, Ren GY. Urban heat island intensity in Wuham, China. IAUC Newsletter 2006;17:7-8.

13. Kovats RS, Akhtar R. Climate, change and human health in Asian cities. Environ Urban 2008;20:165-75.

14. Stone B, Norman J. Land use planning and surface heat island formation: A parcelbased radiation flux approach. Atmos Environ 2006;40:3561-73.

15. Zhang YC, Rossow WB, Lacis AA. Calculation of surface and top-of-atmosphere radiative fluxes from physical quan22. CBS. Statistical abstract. Nairobi: Central Bureau of Statistics ed.; 2003. 